\section{Can audit improve patient care and treatment outcomes in endodontics?}

\author{
D. Simons ${ }^{* 1}$ and D. Williams ${ }^{1}$
}

IN BRIEF
- Allows readers to consider whether the
clinical audit cycle in NHS dentistry is a
valuable tool for implementing change
and addressing educational need.
- Discusses how to disseminate audit
results to participating dental teams and
appropriate training for these teams.
- Stimulates discussion about published
endodontic standards improving process
but not necessarily outcomes for root
treated teeth in special care patients.

Clinical audit is part of the NHS clinical governance framework for dentistry and is recommended as a quality improvement process for patient care, yet there is very mixed evidence supporting audit's ability to produce change in practice. Findings show evidence of changes following audit which improved patient care and practice efficiency. However, there is a general lack of dissemination of audit results, little useful feedback provided to participants, limited use of formal re-auditing of a particular topic and little reported on whether audit improves outcomes for patients. As part of its clinical governance responsibility, the Community Dental Service (CDS) is committed to ensuring that its clinical audit is robust, strategic and measures patient outcomes in its evaluation. The aim of this paper is to present a complete endodontic audit cycle; its recommendations and effects on the process and on outcomes of clinical patient endodontic care; and to evaluate if audit was a useful tool in this case.

\section{INTRODUCTION}

Clinical audit is a quality improvement process that seeks to improve patient care and outcomes through systematic review of care against explicit criteria and the implementation of change. Aspects of the structure, processes and outcomes of care are selected and systematically evaluated against explicit criteria. Where indicated, changes are implemented at an individual, team or service level and further monitoring is used to confirm improvement in healthcare delivery. ${ }^{1}$ Clinical audit can be described as a cycle/spiral (see Fig. 1). ${ }^{1}$ Within the cycle there are stages that follow a systematic process of establishing best practice, measuring care against criteria, taking action to improve care and monitoring to sustain improvement. The spiral suggests that as the process continues, each cycle aspires to a higher level of quality. Collecting data for a second time, after changes have been introduced, is central to both assessing and maintaining the improvements made during clinical audit. ${ }^{1}$ The same procedures of

'Dental administration, 3rd Floor B Block, St. Leonards Hospital, Nuttall Street, London, N1 5LZ

${ }^{*}$ Correspondence to: Debra Simons

Email: debra.simons@bartshealth.nhs.uk

\section{Online article number E25}

Refereed Paper - accepted 18 March 2013

DOI: 10.1038/sj.bdj.2013.434

${ }^{\circledR}$ British Dental Journal 2013; 214: E25

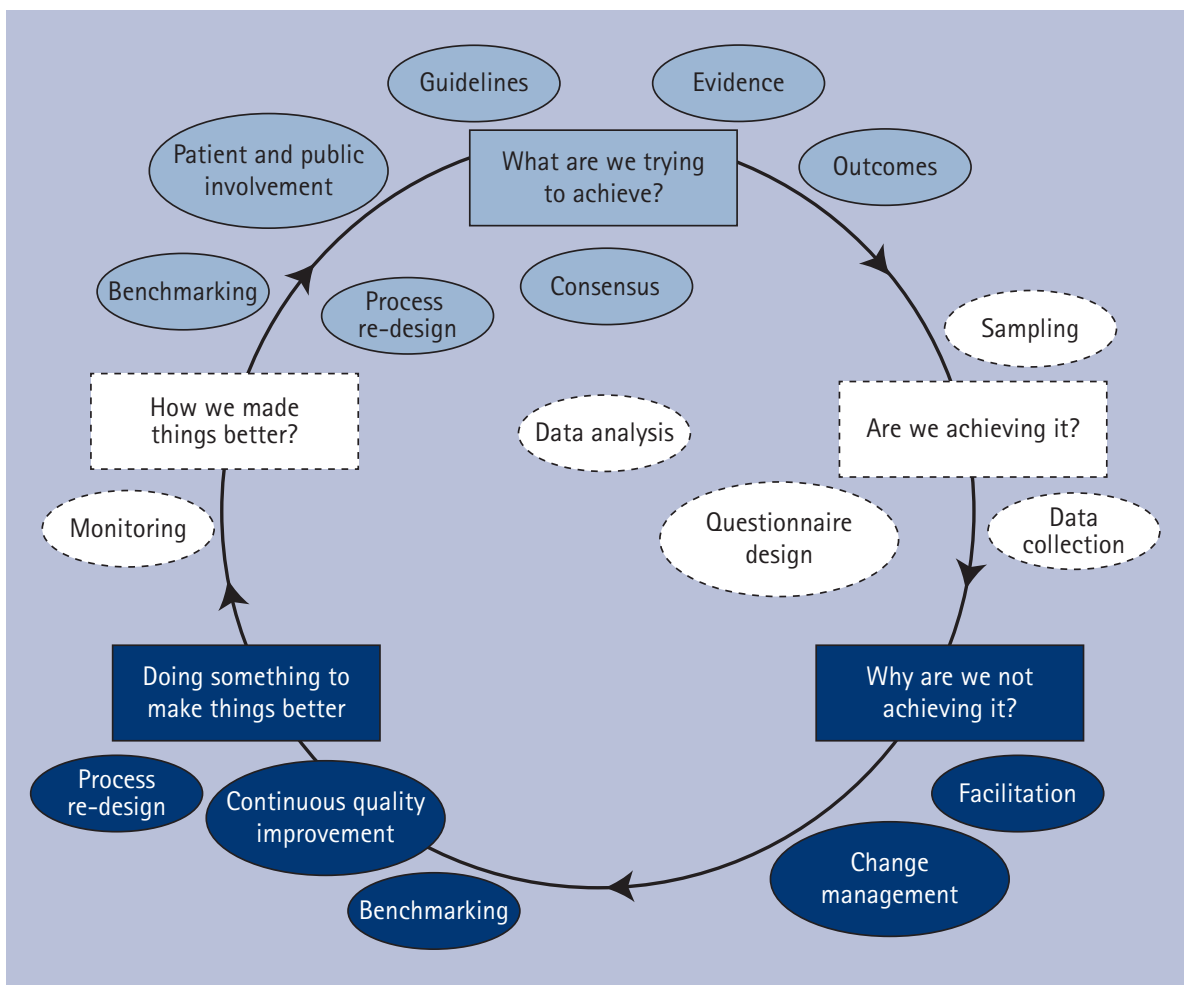

Fig. 1 Audit cycle

sample selection, information collection and analysis are conducted.

However, the evidence for audit being a successful tool to improve performance is not strong. A systematic review concluded that providing healthcare professionals with data about their performance in the form of audit and feedback may help improve their practice. ${ }^{2}$ However, the effects varied widely, from an apparent negative to a very large positive effect. The review concluded that the relative effectiveness of audit and feedback was likely to be greater when baseline adherence to recommended practice was low and when feedback was delivered more 
intensively. The evidence presented in the review did not support mandatory use of audit and feedback as an intervention to change practice. ${ }^{2}$ However, clinical audit is part of the NHS clinical governance framework for dentistry ${ }^{3}$ and is a terms of service requirement. As part of its clinical governance responsibility, the Community Dental Service (CDS) is committed to ensuring that its clinical audit is robust and strategic so that it:

1. Provides assurance of compliance with clinical standards

2. Identifies and minimises risk, waste and inefficiencies

3. Improves the quality of care and patient outcome

4. Includes all of the clinical audits necessary to meet regulatory and commissioner requirements.

Within this programme the audit of endodontic treatment provided by the CDS of Tower Hamlets and City \& Hackney is evaluated. The CDS provides the full range of NHS dental care for special needs ${ }^{4}$ patients, treating a diverse client-group with a range of disabilities and complex additional needs, with and without oral, inhalation and intravenous sedation.

The aim of endodontic treatment is to preserve functional teeth without prejudice to the patient's health. ${ }^{5}$ The European Society of Endodontology has developed guidelines on the standard of care which are intended to represent current good practice. ${ }^{5-7}$ Every dental practitioner is expected to be able to recognize and treat effectively, pulpal and periapical injuries. ${ }^{6}$ The cases that are beyond an individual dental practitioner's means concerning diagnostic and/ or technical alternatives should be referred to a colleague who has acquired the necessary expertise. ${ }^{7}$ The UK literature contains studies on the outcome of non-surgical endodontic treatment, which has been reported to have a success rate of 53-95\% over various periods of observation, ${ }^{8}$ and audits of endodontic treatments performed by NHS dentists, dental students and private dentist's exist ${ }^{9 .-15}$ However publications of completed audit/re-audit cycles seem rare. ${ }^{3}$ Collecting data for a second time, after recommendations have been made and changes introduced, is one way to assess if the audit has any value at improving outcomes for the patients.
The aim of this paper is to present a complete endodontic audit cycle, its recommendations, and the audits effects on the process, and outcomes of clinical patient endodontic care. The goal was to evaluate if audit was a useful tool in this case.

\section{METHOD}

The endodontic audit within the CDS has undergone a full cycle; an initial audit in 2005 was repeated in 2011 using the same audit tool. The tool was developed using valid criteria ${ }^{6-7}$ based on evidence, related to important and measureable aspects of care. ${ }^{1}$ In both 2005 and 2011, 20 clinicians were involved in the audit. In the previous 12 months patient record cards were examined and where possible ten cards containing root canal treatments were selected in reverse date order for each clinician. It was understood that not all the clinicians would have completed endodontic treatment on ten teeth; however the aim was to audit a minimum of 50 teeth and a maximum of 200. Each record card and the related radiographs were studied and the audit tool completed by a single dentist. The audit tool was divided into four main areas as follows:

\section{Clinical standards during endodontic treatment}

Good clinical practice is to take comprehensive notes recording history, clinical signs, symptoms, radiographic and special tests results, diagnosis and treatment plan, including the use of rubber dam and materials that are used. The use of rubber dam is a medico-legal as well as clinical requirement and all endodontic procedures should be carried out with appropriate airway protection. Records should contain notes on the working length of canals and their reference points, the size to which canals are prepared, preparation technique, volume and concentration of irrigation used, dressing applied, type of temporary restoration, root filling material, sealer and technique..$^{5-7}$

\section{Radiographs taken during endodontic treatment}

Guidelines advise that radiographs should be taken and reported on. These should be pre-operative, working length (WL) radiographs (if there is no reliable apex locator reading), an immediate post-op radiograph and a follow-up radiograph at 1-4 years.

\section{The quality of root canal filling as determined radiographically}

Examination of the quality of root filling radiographically includes: the apical extent of root canal treatment in relation to the radiographic apex, the prepared and filled canal should contain the original canal, no space between canal filling and canal wall should be seen. There should be no canal space visible beyond the end-point of the root canal filling. ${ }^{5}$

\section{Clinical outcomes and adverse events}

The following findings indicate a favourable outcome: absence of pain, swelling and other symptoms, no sinus tract, no loss of function and radiological evidence of a normal periodontal ligament space around the root. ${ }^{5}$ The tooth should be adequately restored to prevent bacterial recontamination of the root canal system or fracture of the tooth, the coronal seal is increasingly recognised in the literature as a factor influencing endodontic success. ${ }^{6-7}$

\section{RESULTS}

In 2005 a total of 53 teeth from 42 patients were analysed. The patients' ages ranged from 14 to 67 years and there were 24 males and 18 females. The types of teeth included in the audit were 10 (19\%) incisors, 1 canine (2\%), $32(60 \%)$ premolars and 10 (19\%) molars. In 2011 a total of 108 teeth from 96 patients were analysed. The patients' ages ranged from 14 to 84 years and there were 44 males and 52 females. The types of teeth included in the audit were 26 (24\%) incisors, 12 (11\%) canines, 37 (34\%) premolars and 33 (31\%) molars. The audit standards in 2005 were compared with those in 2011 (Tables 1-4).

\section{DISCUSSION}

The results from the 2005 audit highlighted that either clinical actions were below expected standards or that the recording of these actions was below these standards, this led to recommendations being made and then implemented throughout the service. The initial action was feedback to all the clinicians of the results of the audit. Within the CDS audit findings are fed back to the whole team, a suggestion 


\begin{tabular}{|c|c|c|}
\hline $\begin{array}{l}\text { STANDARD } \\
\text { There was a record in the notes that: }\end{array}$ & $\begin{array}{l}\% \text { Achieved } \\
2005 \\
(n=53)\end{array}$ & $\begin{array}{l}\% \text { Achieved } \\
2011 \\
(n=108)\end{array}$ \\
\hline $\begin{array}{l}\text { A thorough examination had been carried out on the } \\
\text { endodontically involved tooth for example, sinus, swelling }\end{array}$ & 33.9 & 52.7 \\
\hline A vitality test had been undertaken & 13.2 & 6.5 \\
\hline Rubber dam was used & 35.8 & 78.7 \\
\hline $\begin{array}{l}\text { When there was no record of rubber dam use there was a record } \\
\text { in the notes that other aids had been used that is, parachute chain }\end{array}$ & 0 & 25 \\
\hline An irrigant was used and named & 67.9 & 84.3 \\
\hline An intracanal medicament was used and named & 76 & 86.2 \\
\hline An apex locater had been used & 35.8 & 47.2 \\
\hline The working length had been recorded & 96.2 & 85.2 \\
\hline
\end{tabular}

\begin{tabular}{|c|c|c|}
\hline Radiographs & $\begin{array}{l}\% \text { Achieved } \\
2005(n=53)\end{array}$ & $\begin{array}{l}\% \text { Achieved } \\
2011(n=108)\end{array}$ \\
\hline A pre-op/diagnostic periapical radiograph had been taken & 64.1 & 87.9 \\
\hline $\begin{array}{l}\text { There was a written report on the radiographic findings in the } \\
\text { record card }\end{array}$ & 52.9 & 64.2 \\
\hline A WL radiograph had been taken & 45.3 & 49 \\
\hline A master gutta percha point or mid fill radiograph had been taken & 11.3 & 45.4 \\
\hline A post obturation radiograph had been taken & 67.9 & 85.2 \\
\hline Radiograph quality was grade $A$ & 94 & 98 \\
\hline
\end{tabular}

Table 3 The quality of root canal filling as determined radiographically

\begin{tabular}{l|l|l}
\hline $\begin{array}{l}\text { The radiograph showed: } \\
\begin{array}{l}\text { The root canal filling was between 0-2 mm from the } \\
\text { radiographic apex }\end{array}\end{array}$ & $\begin{array}{l}\text { \% Achieved } \\
2005(\mathrm{n}=36)\end{array}$ & $\begin{array}{l}\text { \% Achieved } \\
2011(\mathrm{n}=92)\end{array}$ \\
\hline $\begin{array}{l}\text { The root canal filling had extend past through the radiographic apex } \\
\text { The root canal filling was more than } 2 \mathrm{~mm} \text { from the } \\
\text { radiographic apex }\end{array}$ & 9.7 & 21.8 \\
\hline $\begin{array}{l}\text { The root canal filling was well condensed and demonstrated a good } \\
\text { tapered preparation }\end{array}$ & 45.2 & 20.7 \\
\hline $\begin{array}{l}\text { There were some voids but overall the root canal filling was assessed } \\
\text { as satisfactory }\end{array}$ & 29 & 53.7 \\
\hline \begin{tabular}{l} 
The root canal filling was poorly condensed \\
\hline
\end{tabular} & 26 & 20.4 \\
\hline
\end{tabular}

Table 4 Clinical outcomes adverse events

\begin{tabular}{|l|l|l|}
\hline Event & $\begin{array}{l}\% \text { Achieved } \\
2005(n=53)\end{array}$ & $\begin{array}{l}\% \text { Achieved } \\
2011(n=108)\end{array}$ \\
\hline The tooth was extracted & 1.9 & 11 \\
\hline Instrument separated in the canal & 1.9 & 0 \\
\hline Patient experienced pain, lost dressings & 9.4 & 15.7 \\
\hline A permanent plastic restoration had been placed & 60 & 75 \\
\hline $\begin{array}{l}\text { A cast cuspal coverage restoration had been placed in either molar } \\
\text { or premolar }\end{array}$ & 14.3 & 7.1 \\
\hline
\end{tabular}

supported by Cannell. ${ }^{3}$ Recommendations started with the improvement of record keeping, Dentists needed to be recording clinical signs in 100\% of cases. In 2005 clinical signs were not recorded in two thirds of cases and vitality test results were only recorded in 13\% of cases. In 2005 the use of rubber dam was only recorded in $35.8 \%$ of the record cards and if alternatives such as parachute chain or other aids were used this was not documented. Rubber dam should always be used to prevent salivary and bacterial contamination, prevent inhalation and ingestion of instruments and prevent irrigating solutions escaping into the oral cavity, ${ }^{5}$ and its use should be documented in the record card. Only in exceptional cases would non-use be permitted and an alternative such as a parachute chain or floss must be used. The reason for non-use must be clearly documented in the record card. Clinicians were encouraged to use the endodontic custom screens on the computer system to improve record keeping and training was implemented in the responsibility of good record keeping, informed consent, ethics and medico-legal matters. Every CDS clinic had its stock checked and additionally supplied with electric pulp testers, apex locators and latex-free rubber dams.

In 2011 the use of rubber dam was recorded in $78.8 \%$ of the notes. In the $21.2 \%$ of the cases in which it wasn't used/ recorded, alternatives such as parachute chain or other aids were documented in only 25\% of the notes. Although 100\% was not reached this compares favourably to the responses ${ }^{17}$ received from 449 primary care dentists, showing only 30\% of them used rubber dam for isolation in all endodontic cases and only 3.4\% of Flemish dentists report using it as a standard procedure. ${ }^{11}$ The Flemish study indicated the discrepancies between daily practice and academic teaching, especially regarding the use of rubber dam and the detection and preparation of a second mesiobuccal canal in maxillary first molars (70\% never or seldom), many Flemish general practitioners were not following quality guidelines for endodontic treatment. ${ }^{11}$

An accurate diagnosis is an important aspect of endodontics and vitality tests are essential aids to arriving at the correct diagnosis. Ideally, several tests should be used in conjunction to give an overall 
picture. Conventional vitality tests assess conduction of nerves in the pulp and are therefore not strictly vitality tests but rather sensibility tests. These include cold thermal, heat thermal and electrical tests. Despite training and the purchase of 'blue ice' and electric pulp testers in 2005, after the first audit, the recording of vitality test reduced to $6.5 \%$ in 2011 . However, record keeping on signs and symptoms improved to $52.7 \%$ in the re-audit and it appears that there was a reliance on radiographs for diagnosis. The audit in 2011 showed the taking of and reporting on radiographs was greatly improved, with only $12 \%$ of cases without an available preoperative radiograph. Although a radiograph may indicate the presence of pathology, a disadvantage of the use of radiography in diagnosis can be that the early stages of pulpitis are not normally evident on the radiograph. However, it maybe that for the special care patients seen within the CDS, it was the perceived clinical view that a combination of preoperative radiograph and other signs and symptoms, such as tender to percussion, were more suitable diagnostic indicators than vitality tests, which can often be variable with the anxiety of the patient. The objective should be the accurate determination of pulpal vitality or nonvitality, along with the recording of this in the notes. This was improving by 2011 and errors lay within a few specific dentists only, those who still had no access to computer held records. The CDS is trying to obtain the funding for a single computer system across all clinics and it is envisaged that this will aid record keeping for all patient records. When the results of the re-audit were relayed to all clinician's the largest barrier they identified was lack of computer access.

Radiographs taken in both audits were of good quality, with only 6\% of radiographs not showing the apex/apices in 2005 reducing to $2 \%$ by 2011 . The audit in 2011 showed the taking of and reporting on radiographs were greatly improved, with $12 \%$ of cases without a preoperative radiograph, 51\% without a WL radiograph and in only $8 \%$ of these, was there no evidence of an apex locator having been used instead. Only 15\% of cases did not have a post-operative radiograph and some notes had stated it had been taken but the radiograph could not be found. The quality of root canal filling was determined from available radiographs and in 2005, 35.5\% cent of root fillings were under extended (more than $2 \mathrm{~mm}$ from radiographic apex), $54.8 \%$ were a satisfactory length (between 0-2 $\mathrm{mm}$ from the radiographic apex) and 9.7\% extended through the radiographic apex. These results were comparable to those reported from a study within the armed forces, the respective figures being $32 \%$, 50\%, and $18 \% .{ }^{10}$ The level of root filling in relation to the root apex has a significant influence on outcome for teeth with apical periodontitis. In a long-term, follow-up study, non-vital teeth with apical periodontitis that were instrumented and filled to the apex had a success rate of $94 \%$, whereas teeth with the same preoperative status that were overfilled had success rate of $76 \%$, and those that were filled short ( $>2 \mathrm{~mm}$ ) of the root apex had a success rate of $68 \%$. This confirms the importance of debriding the apical portion of $0-2 \mathrm{~mm}$ from the apex and obturating to this length. ${ }^{18}$

Forty-five percent of root fillings were well condensed and had a good taper, 29\% were satisfactory with some voids and had a satisfactory taper, and 26\% were poorly condensed and poorly tapered. Overall $55 \%$ of obturations in the root filled teeth were deemed satisfactory in homogeneity and length. ${ }^{5}$ In a radiographic assessment of root fillings performed in general dental practice only 10\% of cases were classified as satisfactory. ${ }^{9}$ Endodontics is an exacting discipline, and has been identified as one of the most technically demanding procedures in general dental practice. ${ }^{19}$ As a result of the 2005 audit findings an endodontic hands-on course was developed. It has been recommended that perceived and actual barriers must be addressed in planning and delivering training in endodontic techniques, the opportunity for 'hands-on' practice of new methods is needed. It has been suggested that peers and colleagues should act as educators, because of their in-depth knowledge of the practice setting. Programmes of continuing education need to be flexible, to take into account differences in learners' needs, learning styles and working environment. Using a combination of different educational methods is said to improve the chances of successful implementation of change. ${ }^{17,19}$
The training was therefore delivered in small groups, starting with lecture format and then moving to within the dental surgeries, the first part was a basic introduction to endodontics including the use of hand files and cold lateral condensation. The practical component was then extended to include additional days so that skills could be consolidated and the use of rotary instruments was included. Training was given on restoration of the root filled tooth and shadowing sessions for dentists, as well as induction sessions for new dentists, with the service endodondist and the service prosthodontist were provided. Another dentist was supported on a 'certificate' course in endodontics and then presented an endodontic update to the wider team. Guidelines were produced on endodontics for patients who required sedation and peer review was conducted with record cards and radiographs.

However, the audit of 2011 revealed that the percentage of root fillings of optimal length and homogeneity was not improved and more were over-extended, 26\% were still considered unsatisfactory. Although procedure had improved between 2005 and 2011, outcomes as determined by post-operative radiographs had not. Tickle et al. in $2008^{14}$ argue that the appearance of the root filling on the radiograph is not a valuable outcome measure. In their study reporting the outcomes of NHS-funded molar endodontic treatment provided by GDPs approximately one quarter of teeth (26.6\%) were judged to have been root filled to an optimal standard, whereas $38.2 \%$ of root fillings were considered to be sub-optimal, 35.3\% had no post-operative radiograph or the radiograph available was unreadable. The most surprising finding was that virtually the same proportions of teeth failed in those categorised as having optimal (8.7\%) or sub optimal root fillings (9.1\%) and in those teeth with no film or an unreadable film (9.8\%). The results suggested that endodontic treatment is not as technique sensitive as previously thought and concluded that the quality of the root filling had little impact on outcomes. They argued that GDPs are unlikely to extract teeth or replace a root filling unless the patient is experiencing recurrent and severe symptoms, and so that the outcome measure should be patient related, such as pain, which is more important for 
patients than professionally assessed outcome measures. They felt that a more lucid understanding of the relationship between radiographically judged pathology and subjectively assessed (patient judged) success of endodontic therapy is required. ${ }^{14}$

Tickle et al. ${ }^{14}$ agreed with other research that the importance of coronal seal is paramount. ${ }^{20}$ Based on the data available from a meta-analysis, four conditions were found to significantly improve tooth survival. In descending order of influence, the conditions increasing observed proportion of survival were: (i) a crown restoration after root canal treatment; (ii) tooth having both mesial and distal proximal contacts; (iii) tooth not functioning as an abutment for removable or fixed prosthesis; and (iv) tooth type or specifically non-molar teeth. ${ }^{21}$ However, in the audit in 2005 only $14 \%$ of molar or premolar endodontically treated teeth had been restored with a cast cuspal coverage restoration and this fell even further in 2011 to 7\%. This may explain why more adverse events occurred in 2011 compared to 2005, with 11\% of teeth needing extraction after the root canal treatment had commenced, as 90\% of the teeth extracted were uncrowned premolars and molars.

Contributing factors could be that during 2005 to 2011 the patients being seen by the CDS have become more complex, with increasing special care needs. More molar root treatments were completed, 31\% in 2011 compared to $19 \%$ in 2005 , and $26 \%$ of the patients had some form of sedation, either inhalation or intravenous, yet no one had sedation in 2005. The dentists also had completed endodontic training which may have resulted in them becoming more ambitious in the teeth they attempted root canal treatment on, or the patients may have been more determined to retain teeth rather than accept extraction. The endodontic audit and resulting action plan and training obviously failed to address any limitations in skills or knowledge which may be part of the barrier to provision of crowns in special care patients or it may be that the NHS charges that were introduced to CDS between 2005 and 2011 meant patients were prepared to pay for a Band 2 treatment (root canal filling) but not a Band 3 treatment (crown).

\section{CONCLUSION}

It is widely accepted that for many dental practitioners the practice of endodontics is challenging and technically demanding. In the UK, this has been highlighted in studies on endodontics in the NHS, which often show standards falling short of what is considered as current best practice. ${ }^{5}$ Dummer showed that only 10\% of cases treated by UK general dental practitioners could be considered as acceptable with reference to the guidelines. ${ }^{9}$ This endodontic audit cycle, on special care patients treated within the CDS, showed that again not all the guidelines were adhered to, despite training that addressed earlier audit findings. This study showed that although processes 'improved', patient-centered outcomes, such as, pain, lost dressings and tooth loss did not. In 2005, 98\% of teeth survived compared to $89 \%$ in 2011 . The audit cycle taught us that:

- Audit was valuable as a tool to improve process, but in this case did not improve patient outcome

- Quality guidelines for dental clinical treatments should have patient involvement in outcomes, and consider more what the treatment is trying to achieve

- Evidence for clinical treatment is constantly evolving and therefore, continuing education and the quality of that education needs to be repeatedly evaluated to result in compliance with good practice

- Audit tools need to adapt and develop as new evidence becomes available; what was fit for purpose at one time may not be applicable 5 years later

- Further training is required and the audit should be repeated again, but only after the barriers to compliance with published guidelines have been identified and where possible addressed.

1. National Institute for Clinical Excellence. Principles for Best Practice in Clinical Audit. Milton Keynes:
Radcliffe Medical Press Ltd, 2002

2. Jamtvedt $G$, Young J M, Kristoffersen DT, O'Brien M A, Oxman A D. Audit and feedback: effects on professional practice and health care outcomes. Cochrane Database Syst Rev 2006; 2: CD000259.

3. Cannell P J. Evaluation of the end user (dentist) experience of undertaking clinical audit in the post April 2001 general dental services (GDS) scheme BrDent J 2012: 213: E7.

4. Joint Advisory Committee for Special Care Dentistry (JACSCD). A case for need: proposal for a Specialty in Special Care Dentistry. London: JACSCD, 2003.

5. European Society of Endodontology. Quality guidelines for endodontic treatment: consensus report of the European Society of Endodontology. Int Endod J 2006: 39: 921-930.

6. European Society of Endodontology. Undergraduate curriculum guidelines for endodontology. Int Endod J 2001; 34: 574-80.

7. European Society of Endodontology Guidelines for specialty training in endodontology. Int Endod J 1998; 31: 67-72.

8. Friedman S. Treatment outcome and prognosis of endodontic therapy. In Örstavik D, Pitt-Ford TR (eds). Essential endodontology. pp 367-401. Malden, MA: Blackwell Science, 1998.

9. Drummer P M H, (J Dent Pract Board Eng Wales). The quality of root canal treatment provided by general dental practitioners working within the general dental services of England \& Wales. Part 2. Dental Profile 1998; 19: 8-10.

10. Peak J D, Hayes S J, Bryant S T, Drummer P M H. The outcome of root canal treatment. A retrospective study within the armed forces (Royal Air Force). Br Dent J 2001; 190: 140-144.

11. Slaus $G$, Bottenberg P. A survey of endodontic practice among Flemish dentists. Int Endod J 2002; 35: 759-767.

12. Barbakow F H, Cleaton-Jones P E, Friedman D. An evaluation of 566 cases.of root canal therapy in general dental practice. 1. Diagnostic criteria and treatment details. J Endod 1980; 6: 456-460.

14. Hayes S J, Gibson M, Hammond M, Bryant S T, Dummer P M H. An audit of root canal treatment performed by undergraduate students. Int Endod $J$ 2001; 34: 501-505.

15. Tickle M, Milsom K, Qualtrough A, Blinkhorn F, Aggarwal V R. The failure rate of NHS funded molar endodontic treatment delivered in general dental practice. Br Dent J 2008; 204: E8.

16. Salehrabi R, Rotstein I. Endodontic treatment outcomes in a large patient population in the USA: an epidemiological study. J Endod 2004; 30: 846-850.

17. Lazarski M P, Walker W A, Flores C M, Schindler W G, Hargreaves K M. Epidemiological evaluation of the outcomes of nonsurgical root canal treatment in a large cohort of insured dental patients. J Endod 2001; 27: 791-796.

18. Palmer N O, Ahmed M, Grieveson B. An investigation of current endodontic practice and training needs in primary care in the north west of England. Br Dent J 2009; 206: E22.

19. Sjogren U, Hagglund B, Sundqvist G, Wing K. Factors affecting the long-term results of endodontic treatment. J Endod 1990; 16: 498-504.

20. McColl E, Smith M, Whitworth J, Seccombe G, Steele J. Barriers to improving endodontic care: the views of NHS practitioners. Br Dent J 1999; 186: $564-568$

21. Ray H A, Trope M. Periapical status of endodontically treated teeth in relation to the technical quality of the root filling and the coronal restoration. Int Endod J 1995; 28: 12-18.

22. Ng Y L, Mann V, Gulabivala K. Tooth survival following non-surgical root canal treatment: a systematic review of the literature. Int Endod J 2010; 43: 171-189. 